\title{
A New Type of Luminescence in Fishes. II.
}

\author{
By
}

\author{
C. F. Hickling, B.A.,
}

Department of Oceanography, Liverpool University.

With 2 Figures in the Text.

THE experiments described in the present paper were carried out during the winter months of 1925-6 on the steam trawler Tamura, by the courtesy of Messrs. Neale and West, Ltd., of Cardiff. I am especially indebted to Captain Drennan, not only for the facilities for work which he provided, but for his continual encouragement in the difficult conditions under which most of the work was done. I am also greatly indebted to Professor E. Newton Harvey, whose correspondence has suggested the lines of the work, and to Professor Ramsden, of the Biochemical Department of Liverpool University, for criticising the results.

\section{The Secretion.}

The gland and the structure of the luminiferous epithelium of Malacocephalus lavis were described in a previous paper (1925). To that description it is necessary to add a note concerning the nerve supply of the gland. Careful examination has led to the belief that there is no special nerve passing to the gland, especially from the rectum. There is a network of nerve cells in the connective tissue capsule of the gland, from which fibres pass up into the folds of tissue which project into the lumen; this network seems to be supplied by nerves arising from the dermis below the gland. The actual secreting activities of the gland are largely controlled, in my opinion, by other agencies, such as the blood supply.

As described in the earlier paper, the secretion arises in the cells lining the folds of tissue. It appears as fine granules lying in the cytoplasm between the nucleus and the external surface of the cell, and the appearance of a cell partially charged with granules is strikingly similar to that of the cells of the salivary glands figured by Bowen (1925). In fact, it is often possible to make out darkly staining masses in the neighbourhood of the nucleus, which may be indications of a network of Golgi bodies. In any case, secretion in the two cases seems to be closely similar.

$$
\text { NeW series.-VOL. Xiv. No. 2. AUGUST, } 1926 .
$$


Förster (1912), describing the formation of the granules in the secreting cells of Pholas, shows that they arise between the meshes of a network in the cytoplasm. The granules of Pholas, like those of $M$. lavis, have a clear central part which does not stain deeply with iron-hæmatoxylin, and an outer layer which stains very deeply.

The granules appear first near the nucleus, but multiply very rapidly in number, and soon form a dense mass which bulges out into the lumen of the gland. This process is figured somewhat diagrammatically in Fig. 1. There are comparatively few intermediate stages, so that the formation of the granules would seem to be very rapid. There is no indication that a spent cell can ever regenerate a fresh crop of granules.

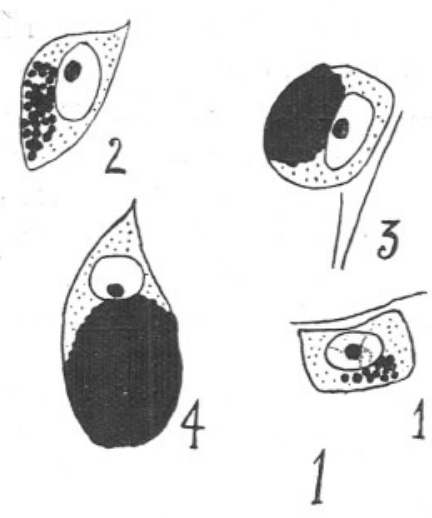

Fra. 1.-Four stages in the appearance of the luminiferous granules in the cells of the ventral gland of $M$. lavis. In 3 and 4 they form a dense mass.

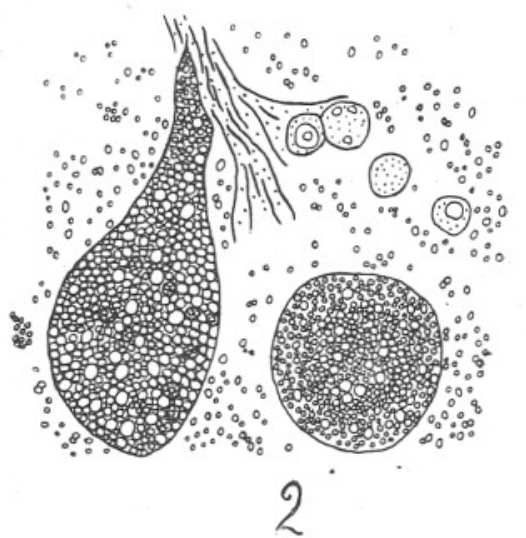

FIG 2.-The appearance of a fresh suspension of the secret on, fixed in formalin. Two globes are seen with fragments of connective tissue and some broken-down epithelial cells. Very numerous granules are also seen.

Towards the exit of the gland the tissues are seen to be breaking down, and the mass contains great numbers of secreting cells, with large nuclei, none of which bear any granules. In such glands the portion of the gland which is still actively secreting is at the periphery, as described previously.

This may be compared with the account of the luminous organs on the lower jaw of Monocentris given by Okada (1926). He finds that the epithelium of the secreting tubules is completely destroyed in the process. of secretion, but that it is replaced by the constant proliferation of the cells at the base of the tubules. In this fish, also, the secretion is granular, but Okada was not able to trace its formation in the secreting cells. Since in both Pholas and M. lavis the appearance of the secretion is 
sudden, it is possible that the rare intermediate stages may have been overlooked.

When a drop of fresh secretion, squeezed from a specimen of $M$. lavis, is examined under the microscope, it is seen to consist mainly of a dense mass of globular bodies (henceforward to be referred to as globes) measuring between 30 and $40 \mu$, but rather variable in size. These are identical with the clumps of secretion seen in sections, but in the fresh condition one notices what was then missed, namely, that the clumps of granules, when they burst from the mother cell, are still enclosed in a cytoplasmic sheath. The secretion, as obtained in this way, also contains fragments of the other tissues of the gland, such as strips of connective tissue, and many spent secreting cells. The appearance of a suspension of the gland, as fixed in formalin, is indicated in Fig. 2.

The globes are seen to be rapidly breaking up, and the process is much more rapid if a drop of secretion is placed in contact with a drop of seawater. Each globe is usually somewhat pear-shaped, and rupture seems to occur most commonly at the stalk. The enclosed granules escape, and increase in size to a marked extent when set free. They now appear as highly refractive oval bodies, each between 1 and $2 \mu$ in length, which show a distinct greenish fluorescence. They seem to have a fluid interior bounded by a membrane. In my view, these granules are the actual source of luminescence.

The plasmatic envelope is seen especially distinctly if the globe happens to adhere to the slide; the rolling of the ship, which causes the whole body of fluid in the drop to move from side to side, soon draws the sheath out into a stalk, at the end of which the clump of granules is suspended.

If a suspension of the secretion in a drop of sea-water is examined under the microscope in the dark, groups and chains of brilliant green globes can be seen, but by working in suitable conditions of light and darkness it is found that not all the globes seen under ordinary illumination, are luminescent. Only those which are actually breaking up, and where the escaping granules are still in a mass, are visible as points of light. In an older solution there is no longer any luminous object upon which one can focus, the reason being apparently that each individual granule does not give out sufficient light to be seen under the microscope, a fact which is also true of luminous bacteria. In an older solution, in which all the globes have broken up, the granules are scattered throughout the fluid.

The globes all break up and allow the granules to escape in the natural course of events, but the process is greatly hastened by shaking, which causes mechanical rupture of the envelope. To the naked eye the change, on shaking, is one from a liquid containing very numerous points of bluish light, to one exhibiting a uniformity diffuse bright green lumines- 
cence. It is at this point that the light is most brilliant. Breaking up of the globes, however, probably takes place in natural conditions by the mechanical violence of ejection of the secretion.

\section{The Effect of Fresh or Distilled Water.}

Fresh or distilled water at once puts out the light of the secretion when this is poured into it. Examination under the microscope shows that the plasmatic envelopes of the globes undergo instant cytolysis, while the granules remain in masses; but as far as observation allows, the granules do not swell to any marked extent, nor appear any different from granules luminescent in sea-water.

If sea-water is added to such a fresh-water suspension of the secretion of $M$. lavis within a few seconds, the light returns, to some extent, but after a couple of minutes an irreversible change seems to have taken place, and no addition of sea-water or hypertonic salt solution will restore the light.

\section{Experiments with Pure Solutions. .}

(a) Sea-water. Three test tubes were set up (i) containing 5 c.c. of sea-water and 5 c.c. of fresh water; (ii) containing 2 c.c. of sea-water and 8 c.c. of fresh water; (iii) containing 1 c.c. of sea-water and 9 c.c. of fresh water. To all three were added roughly equal quantities of secretion. In (i) feeble luminescence took place, but in (ii) and (iii) it was extremely feeble, and extinct in three hours.

This suggested that the first effect necessary for luminescence is a solution of suitable osmotic pressure. It also explained how, if one used a fish which had not been washed with fresh water or wiped, a faint luminescence took place on squeezing the secretion into fresh water.

On the other hand, a hypertonic solution of sea-water, made by adding strong salt solution, soon extinguished the light, and the change was irreversible.

(b) Salt Solutions. It was found that luminescence occurred in distilled water solutions of pure $\mathrm{NaCl}, \mathrm{KCl}$, and $\mathrm{K}_{5} \mathrm{SO}_{4}$, isotonic with sea-water, without any notable difference from the luminescence in sea-water. For the remaining experiments, therefore, distilled water was not used, but the ship's tap water $(\mathrm{pH} 7 \cdot 4)$.

The following substances were used: $\mathrm{KCl}, \mathrm{NaCl}, \mathrm{MgSO}_{4} \cdot 7 \mathrm{H}_{2} \mathrm{O}$, $\mathrm{KNO}_{3}, \mathrm{CuSO}_{4}$, together with cane sugar, alcohol, and glycerine.

Strong solutions of these substances in distilled water were taken out, and from these, by dilution with tap-water, solutions of known strength could be prepared. 
In each case test tubes were set up in a series, such that the solutions contained in them were of increasing strength. To these tubes were then added roughly equal amounts of secretion, and the tube noted which gave the brightest and most sustained luminescence. Owing to the easily understood difficulty of placing quantitatively equal amounts of secretion in each tube, no attempt was made to get anything but an approximate optimum strength in each case.

The results were as follows: copper sulphate, alcohol, and glycerine would not support the luminescence in any concentration, the first probably because of a directly poisonous effect, and the last two, probably because their great permeability renders their presence in water ineffectual in causing osmotic pressure.

The remaining substances will support luminescence as readily as a corresponding amount of sea-water, with a reservation on account of hydrogen ion concentration, as will be explained in the sequel. The optimum strengths, in each case, are given below in the first column; in the second column are given the strengths which De Vries, in his classical experiments with plant cells, found to produce equal effects i.e. to be isotonic with one another.

Cane Sugar.
$\mathrm{MgSO}_{4} \cdot 7 \mathrm{H}_{2} \mathrm{O}$
$\mathrm{KNO}_{3}$
$\mathrm{NaCl}$
$\mathrm{KCl}$

30 per cent.
$5 \quad, \quad$,
$6 \quad, \quad$,
$2 \quad, \quad$,
$2-4 \quad, \quad, \quad$,

$\begin{array}{cc}27-28 & \text { per cent. } \\ 26-28 \quad, \quad, \\ 6-7 \quad, \quad, \\ 3-4 \quad, \quad, \\ 4-5 \quad, \quad, \quad,\end{array}$

There is thus a noteworthy correspondence between the two sets of figures, with the exception of $\mathrm{MgSO}_{4} \cdot 7 \mathrm{H}_{2} \mathrm{O}$, and the solutions are roughly isotonic. But magnesium has a peculiar effect on living matter; Bayliss (1920) quotes several authors who have demonstrated its anæsthetic action, and its use as an anæsthetic in marine biology is well known. Its abnormally low value in the present case may be due to a peculiar effect on the granule membrane. A discussion of all these effects will follow later. As a matter of fact, there is a slight difference in behaviour between e.g. $\mathrm{NaCl}$ and $\mathrm{KCl}$, in duration of luminescence, and possibly these ions differ in their effects on the granules, as Gray (1923) shows that they differ in their action on the cilia of the gills of Mytilus.

It is obvious, therefore, that we are here dealing with an osmotic effect. In suitable conditions osmotically, the luminous material will diffuse out of the granules and luminescence will occur. With solutions of greater or lesser strength luminescence becomes increasingly feeble and short lived.

In all these cases, as long as there is any luminescence taking place, a restoration of the suitable conditions will restore the light to a con- 
siderable extent, but once luminescence has vanished, it cannot be restored.

\section{Effect of Hydrogen Ion Concentration.}

None of the solutions used in the preceding experiments were as brilliant as a corresponding fresh sea-water suspension of the secretion. Now the sea-water was found to have a $\mathrm{pH}$ in the neighbourhood of 8.4 , whereas the artificial solutions were between $7 \cdot 4$ and $7 \cdot 6$. This suggested that, as in so many other cases, acidity inhibits and alkalinity favours oxidation in the present case, since luminescence is undoubtedly an oxidation. To test this, a 2 per cent solution of pure $\mathrm{NaCl}$ in tap water, which was found to support luminescence best, was used. To test tubes of this liquid were added one drop, two drops, and so on of arbitrary solutions of $\mathrm{HCl}$ and $\mathrm{NaOH}$. The $\mathrm{pH}$ was found by the colorimetric method, using solutions which had been treated identically with the above.

At $\mathrm{pH} 9 \cdot 6$ luminescence was brighter than in a corresponding measure of sea-water, and much more sustained. Above this however, luminescence became increasingly feeble, and would probably cease to take place much above ten.

On the other hand, between six and seven luminescence became more and more feeble and short lived, until at $5 \cdot 4$ extinction was almost instantaneous, the secretion being precipitated as a greenish yellow powder. When a portion of this precipitate was neutralised with sodium bicarbonate after half an hour, a feeble light returned, but twelve hours later this process failed to recover the light.

In a similar way, acidifying, after an interval, would not restore the light of a solution which had been extinguished with alkali.

These results with acid solutions suggest that the dimming of a glowing suspension of $M$. lavis secretion is due, in the first place, not so much to an exhaustion of the luminous material, as to an increasing acidity due to the products of its own activity. The change in hydrogen ion concentration of about 150 c.c. of sea-water, to which the secretion had been added, was observed at four-hour intervals by the colorimetric method. The results were :-

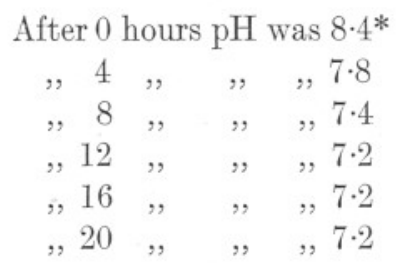

* Values uncorrected for salt error. Correction to be subtracted is $0 \cdot 2$ units. 
Unfortunately, a control experiment with sea-water alone was not done at the same time. Owing to the respiration of the organisms contained in it, fresh sea-water naturally tends to become acid when stood in darkness, and this may have accounted for some part of the rapid decrease in alkalinity found in this experiment.

This change, involving an increase in acidity, was correlated with the brilliance of luminescence. There is always a rapid falling away from the first intense brilliance, though luminescence will continue feebly for as much as six days. Moreover, after eight hours bacteria commence putrefaction of the liquid. A stale suspension swarms with various kinds of bacteria and infusoria.

There is thus reason to believe that, in the very artificial conditions of experiment, the loss in brightness during luminescence is due to the increased acidity (or diminished alkalinity, rather) of the medium.

The acidity may be caused partly by free $\mathrm{CO}_{2}$, for on filtering a suspension of the secretion into a fresh vessel, there is an unmistakable increase in brightness, which in this case might be due to a temporary decrease in $\mathrm{CO}_{2}$ and increase in oxygen during filtration. The effect is temporary only. A filtered solution is extinguished earlier than a non-filtered one, as will be explained below.

\section{The Effect of Calcium Ions.}

It seemed worth while to investigate the effect of calcium ions on the luminescence. It seems that their presence or absence has no effect in this case. Luminescence was bright and sustained in a liquid composed of 7 c.c. of pure $\mathrm{KCl}$ solution isotonic with sea-water, and 3 c.c. of a saturated solution of potassium oxalate. Indeed, there is no reason to doubt that luminescence would have occurred in the pure solution of potassium oxalate.

\section{The Effect of Cytolytic Agents.}

The granules seem highly resistant to cytolytic agents. As mentioned earlier, fresh or distilled water produces no obvious effect, though it destroys at once the plasmatic envelope of the globe. Neither saponin nor sodium glycocholate seemed to produce the slightest effect, either in sea-water or in fresh water. In the former luminescence was as brilliant and as sustained as in ordinary sea-water ; in the latter there was instant extinction, as in the absence of the reagent.

Luminescence was not extinguished on allowing a suspension of the secretion to stand for eight hours over chloroform and carbon tetrachloride, nor was it extinguished by toluene. All these reagents, however, precipitated the luminous material on shaking up, the first two giving a 
thick white sediment, the last named giving a solid plug of white material. This is, no doubt, the luminiferous substance, which is probably protein in nature, and has been coagulated at the surface of the droplets into which the oils break up on shaking. Even so, however, a faint light persists, in the case of carbon tetrachloride, after shaking.

\section{OXYGEN.}

Abundant oxygen is necessary for luminescence. A drop of pure secretion, placed between glass slides, at once becomes dark except at the edge of the drop, which now appears as a bright blue ribbon. As mentioned in the previous paper, a strong suspension of the secretion soon ceases to be luminescent except at the surface. If a test tube full of such a suspension is warmed by the hand, one can see the light creeping down the sides of the tube as convection currents are set up. Also, if one blows small bubbles of air through the dark part of the liquid from a pipette, each droplet gives rise to a dazzling light.

But this phenomenon of "ringing " may appear in an old (acid) solution, and here again the explanation may be that, owing to the acidity of the liquid, conditions suitable for luminescence have again become confined to the surface. Yet oxidation is not notably hastened by the shape of the containing vessel. Luminescence seems to last as long in a flat, shallow jar, as in a tall narrow test tube. This strongly suggests that the dimming of the luminescence is rather due to an inhibition by the products of its own activity, than to a lack of oxygen or an excess of $\mathrm{CO}_{2}$.

\section{EFfect of Light.}

A suspension of the secretion of $M$. lavis was divided into two portions. One was poured into a test tube and hung up in the rigging in bright sunlight. The other was kept below, in darkness. After three hours the exposed tube was brought below and the two solutions were compared. The tube exposed to light was glowing extremely feebly, while the control was in full brilliance. That the effect was not produced by the increased oxidation due to the fresh breeze, was shown when the control was hung in a similar position all night without affecting its brilliance.

\section{Effect of Temperature.}

A jar containing a fresh suspension of the secretion of $M$. laves in seawater was placed in the ice box for several days. On being examined it was found to be very faintly luminescent with a pale blue light. On allowing this liquid to attain air temperature, luminescence reappeared 
as normal. This is the only method so far found for preserving the secretion for any length of time; even here, however, there is slow oxidation, for a suspension which has been preserved in this way does not remain luminescent very long.

At body temperature (approximately $37-38^{\circ} \mathrm{C}$.) extinction is considerably hastened, a test tube being extinct in ten hours at this temperature, where the control was still bright after two days.

When the temperature rises to $47^{\circ} \mathrm{C}$., the light disappears very suddenly, though dimming begins slightly before this. If the tube is plunged into cold water at once, some of the light returns; but destruction of the mechanism of luminescence is very rapid at that temperature, and only a few seconds serves to cause an irreversible change.

At $55^{\circ} \mathrm{C}$. the change is completely irreversible. Luminescence seems, therefore, to follow the usual rule, in that it is hastened up to a certain point, after which the hastening effect is first balanced, and then masked, by destructive effects. There were obvious experimental difficulties in the way of a more accurate determination of the effect of temperature on luminescence. But Harvey (1922) showed that in Photoblepharon and Anomalops, whose light is due to symbiotic bacteria, the light dims at $40^{\circ} \mathrm{C}$. and $38^{\circ} \mathrm{C}$. respectively; and is extinguished at $41-42^{\circ} \mathrm{C}$., and $43^{\circ}$ to $44^{\circ} \mathrm{C}$., respectively. On the other hand, Pholas luciferase is not destroyed until $60^{\circ} \mathrm{C}$. is reached ; in the present case, therefore, dimming and extinction may be associated with a destruction of the properties of the membrane, rather than with any direct effect on the luminiferous materials.

\section{The Effect of Filmration.}

The more thoroughly the suspension is filtered off, the feebler and shorter lived is the luminescence of the filtrate. The filter papers used would not remove all the granules, even when four layers were tried. The filtrate, in this case, was only luminescent for three hours. The temporary effect of filtration in increasing the brightness of luminescence has been referred to.

The filtrate from a suspension of $M$. lavis secretion gives negative results in all experiments tried. It will not give the luciferin-luciferase reaction with a luciferin solution which has also been filtered. Reducing agents will not restore the light $\left(\mathrm{Na}_{2} \mathrm{SO}_{3}, \mathrm{NaNO}_{2}\right)$, though they cause a temporary increase of brightness in a feebly luminescent suspension. Here the effect is probably caused by the alkalinity of these substances. 


\section{CONCLUSIONS.}

Quite apart from any chemical considerations the form in which the luminiferous substances are present in the secretion must be examined. Apparently these are present in the granules, whose origin can be seen under the microscope, and these are set free from their investing sheath of cytoplasm either naturally or by violence. The cytoplasmic sheath plays no important part in luminescence.

In suitable conditions osmotically the luminiferous substances diffuse out of the granules, and in a medium of the right alkalinity, oxidation with luminescence occurs at the surface of the granule membrane. There is very little luminescence free in the medium, since a well-filtered suspension will give a filtrate in which luminescence is very transient; hence the amount of fuel-material free in the fluid at any moment must be very small. This explains the great difficulty experienced in attempting to demonstrate the luciferin-luciferase reaction.

There is an optimum temperature, which is probably low, and the process occurs best in darkness. In natural conditions all these requirements are met, and the great number of granules give an enormous surface area for luminescence, to sustain which there is a continual supply of fresh material diffusing out. This type of luminescence should therefore be a very efficient source of light for whatever purpose it is designed.

In this connection a note by Osorio (1912) is of great interest. He says that Portuguese fishermen use the secretion to smear over pieces of dogfish for use as bait; they believe that the fish are attracted to.the hooks by the light. Osorio considered the light due to bacteria.

In the artificial conditions of experiment the granules never become exhausted, since conditions automatically become unsuitable long before exhaustion occurs. It is therefore impossible to say whether the granules are permanent bodies, or whether they finally dissolve away. They appear quite unchanged after twenty-five hours, during which luminescence has passed its most brilliant phase.

Moreover, the luminiferous materials themselves may be unstable, for on drying the secretion, even at low temperatures over calcium chloride, the power of luminescence is lost, and cannot be regained by moistening with either fresh or salt water. But the act of drying would probably suffice to destroy the permeability of the granules. 


\section{DISCUSSION.}

Each granule of the secretion of $M$. lavis is bounded by a membrane whose permeability depends upon the environment, but which normally keeps the light-producing substances within the granule. It is rendered impermeable by fresh or distilled water, and the change of permeability is irreversible. Hypertonic solutions also cause an irreversible change. The granules differ in this respect from Amoba (Pantin, 1923) and from the cilia on the gills of Mytilus (Gray, 1922), where the change caused by these reagents is reversible, and where complete recovery takes place on restoring suitable conditions. Pantin points out that cytolysis did not take place for some hours when an Amœba was placed in triplestrength sea-water. An irreversible change had taken place in the granules of $M$. lavis in considerably less time than this, but much stronger solutions were used (four or five times the optimum in some cases).

In a similar way the effect of acid may be simply an inhibition of oxidation, as acid inhibits the oxidation of pyrogallic acid, or it may inhibit luminescence by rendering impermeable the granule membrane. Pantin (loc. cit.) shows that increasing the acidity of the medium inhibits contractility in the species of Amœba which he studied, but that the process is completely reversible on transferring to a normal medium. Gray (loc. cit.) finds that a very low $\mathrm{pH}(3 \cdot 4)$ is required to cause complete stoppage of ciliary activity in the gills of Mytilus, and that complete recovery takes place when the medium is made alkaline. The effect of great alkalinity was not studied by Pantin on account of a change which took place in the composition of the medium in such conditions. Probably, its effect on the granule membrane in the present case is to destroy its permeability. It will be noted that the granules themselves are very resistant to cytolysis.

Pantin suggests that, in the case of $A m \propto b a$, " the rise in hydrogen ion concentration may increase the gelation of the protoplasm"; and J. Graham Edwards (1924) shows that the effect of acid on fresh-water amœbæ is to make the surface of the Amœba gelatinous and adhesive, and that the change is irreversible if the action is too prolonged. But Gray considers it "impossible to accept the suggestion that the normal activity of the ciliated cells is upset by acids owing to a disturbance of the cell surface." "Evidence is advanced which suggests that the presence of acid prevents the conversion of chemical energy into kinetic energy."

This effect of acid on the cilia of Mytilus, and the explanation suggested by Gray, might be applied in some measure to the present case. Luminescence must be regarded as a conversion of chemical energy into light 
energy, and the rate of conversion might likewise depend upon the removal of acid, that is, upon the alkalinity of the medium. In vitro a luminescent suspension rapidly increases the acidity of the medium, with a correspondingly rapid fading in the brilliance of the light. In this case, however, the presumed irreversible effect of acid on the granule membrane must also play its part.

The essential difference between the behaviour of a cell and that of these granules seems to lie in the fact that the cell shows great power of recovery, the granules little or none. Usually, once the light has dimmed or vanished there is no means of restoring its former brilliance. I consider that this is due to the readiness with which irreversible changes take place in the granule membrane.

This difference compares in an interesting way with the behaviour of non-nucleated fragments of various Protozoa and algæ, as quoted by Wilson (1925). These fragments likewise lack the power of recovery and regeneration, though destructive metabolism may still continue ; whereas nucleated fragments can regenerate the missing structures and recover their former condition. It suggests that, in both cases, a lack of the power to recover is associated with the absence of nuclear material.

\section{SUMMARY.}

Experiments are described which indicate that there is a physiological problem quite apart from the chemical problem of luminescence in the secretion of Malacocephalus lavis (Lowe). The luminiferous substances are present in granules, which behave as though each were bounded by a membrane whose permeabilities resemble those of a typical cell, but differ from a cell in that they have little or no power of recovery from adverse conditions.

For optimal luminescence they require (i) a medium of a certain osmotic pressure, (ii) a certain range of alkalinity, (iii) a certain range of temperature, and (iv) abundant oxygen. Sea-water is not necessary for luminescence.

If they are exposed to extremes of acidity or alkalinity, or of hypotonic or hypertonic solutions, irreversible changes rapidly set in in the membrane of the granule, whereby the power of luminescence is lost.

In artificial conditions the rapid fading of the light from the initial brilliance is probably due to an increasing acidity caused by the accumulation of the products of oxidation. 


\section{LTTERATURE.}

Förster, Johannes. 1912. Uber die Leuchtorgane etc., von Pholas dactylus. Zeitschr. f. Wiss. Zool. 109, p. 349.

Osorio, B. 1912. Une propriété singulière d'une bactérie phosphorescente. C. R. Soc. Biol., Vol. 72. p. 432.

Bayliss, W. 1920. Principles of General Physiology. 3rd Edition. Longmans and Co., London.

Gray, J. 1922. The Mechanism of Ciliary Movement. Proc. Roy. Soc., Series B, Vol. 93, p. 104.

Harvey, E. N. 1922. The production of light by the fishes Photoblepharon and Anomalops. Pub. No. 312. Carnegie Inst. Washington. 1922, c. p. 43.

Pantin, C. F. A. 1923. Physiology of Amœboid Movement. Journ. Mar. Biol. Assoc., N.S., Vol. XIII, No. 1.

Edwards, J. Graham. 1924. The Action of Certain Reagents on Amoboid Movement, II. British Journal of Exp. Biology, Vol. I, No. 4.

Wilson, E. B. 1925. The Cell in Development and Heredity. 3rd Edition. The Macmillan Co., New York.

Hickling, C. F. 1925. A New Type of Luminescence in Fishes. Journal Mar. Biol. Assoc., N.S., Vol. XIII, No. 4.

Bowen, Ropert H. 1926. Studies on the Golgi apparatus in Gland Cells. I, Glands associated with the alimentary tract. Quart. Journ. Micr. Society, N.S., No. 277, Vol. 70, Part I.

OKaDA, Y. K. 1926. On the photogenic organ of the Knightfish (Monocentris). Biol. Bull, Vol. L, No. 5, May, 1926. 
